Relations industrielles

Industrial Relations

\title{
Comparative Labor Movements par GALENSON, Walter, 600 pp. Prentice-Hall, New York, 1952.
}

\section{Gérard Dion}

Volume 8, numéro 2, mars 1953

URI : https://id.erudit.org/iderudit/1022967ar

DOI : https://doi.org/10.7202/1022967ar

Aller au sommaire du numéro

Éditeur(s)

Département des relations industrielles de l’Université Laval

ISSN

0034-379X (imprimé)

1703-8138 (numérique)

Découvrir la revue

Citer ce compte rendu

Dion, G. (1953). Compte rendu de [Comparative Labor Movements par GALENSON, Walter, 600 pp. Prentice-Hall, New York, 1952.] Relations industrielles / Industrial Relations, 8(2), 269-269.

https://doi.org/10.7202/1022967ar

Tous droits réservés (C Département des relations industrielles de l’Université Laval, 1953
Ce document est protégé par la loi sur le droit d'auteur. L'utilisation des services d'Érudit (y compris la reproduction) est assujettie à sa politique d'utilisation que vous pouvez consulter en ligne.

https://apropos.erudit.org/fr/usagers/politique-dutilisation/ 


\section{LIVRES et REVUES}

Travailleurs âgés, sujet traité et publié dans la revue Bulletin Social des Inrustriels, organe de l'Association des Patrons et Ingénieurs de Belgique, 17 rue du Gouvernement Provisoire, Bruxelles, février 1953.

Les progrès de la médecine ont prolongé la vie humaine d'environ une vingtaine d'années. La généralisation des plans d'assurance contre la maladie et les accidents du travail, les nécessités modernes de l'entreprise rendront de plus en plus difficile l'emploi des travailleurs qui n'ont pas encore atteint l'âge de la pension de vieillesse. C'est là un problème général que l'on rencontre dans tous les pays industrialisés. Le numéro de février 1953 du Bulletin Social des Industriels a consacré plusieurs articles à cette question: Le problème du chômeur âgé (André Dreyfuss, m.d.); Le problème tel qu'il se pose en Belgique; enquête de l'Office National auprès d'un certain nombre d'entreprises belges; quelles mesures prendre?; lemploi des travailleurs agés de Grande-Bretagne; Temployé agé aux Etats-Unis. (Jos. M. Becker)

G. D.

"Interpreting the Labor Movement", Industrial Relations Research Association, December 1952. 1 vol. 207 pp., Park and University, Temp. 3, Room 5, Madison 5, Wisconsin. Prix: $\$ 3.00$.

Depuis vingt ans les syndicats ouvriers aux Etats-Unis se sont développés considérablement et ont acquis une importance de plus en plus grande dans tous les secteurs de la vie sociale. En décembre 1950, l'Industrial Relations Research Association avait consacré une partie de son congrès annuel à l'étude de la théorie du mouvement ouvrier et à une appréciation de ses tendances actuelles. Plusieurs spécialistes avaient abordé chacun des aspects du mouvement ouvrier. Ces dix essais ont été publiés sous le titre "Interpreting the Labor Movement". Voici les principaux: Théo- rie du mouvement ouvrier; Structure du mouvement ouvrier américain; Facteurs ethniques dans le développement du mouvement ouvrier américain; La démocratie dans les syndicats; Le rôle du syndicat dans l'industrie, son étendue et ses limites; Politique des syndicats concernant l'unité de négociation; Politique des syndicats concernant les salaires; Attitude des syndicats vis-à-vis des rôles social et économique de l'Etat moderne; Les syndicats et la politique. Les auteurs s'en sont tenus à la théorie pour ne pas dépasser les cadres qui leur étaient assignés.

Ces essais sont d'inégale valeur et comportent nécessairement des répétitions. Mais ils forment l'un des ouvrages qui fournit le plus matière à réflexion sur l'ensemble du mouvement ouvrier aux Etats-Unis. A cause des liens intimes qui existent entre les syndicats américains et les syndicats canadiens, ainsi que de l'influence que l'économie américaine exerce sur l'économie canadienne, personne au Canada ne peut être indifférent à l'évolution et à l'orientation que prennent les syndicats aux Etats-Unis. La lecture de cette interprétation du mouvement ouvrier américain est' absolument indispensable à tous ceux qui veulent comprendre le syndicalisme chez-nous.

$$
\text { G. D. }
$$

Comparative Labor Movements par GALenson, Walter, 600 pp. PrenticeHail, New York, 1952.

Ce volume comprend sept essais dans lesquels on fait la synthèse de l'histoire du mouvement ouvrier en Angleterre, en Scandinavie, en Australie, en Allemagne, en France, en Italie et en Russie. Ces essais ont été préparés par des spécialistes en la matière. Ils font de cet ouvrage le meilleur que nous connaissions sur ce sujet. Nous en recommandons fortement la lecture à tous ceux qui veulent avoir une idée de ce qu'est le mouvement ouvrier dans le monde.

G. D.

\section{BOOKS and REVIEWS}

